\title{
Optimization of PV-Solar Panel Cooling System Performances via Numerical Investigation using a Composite PCM-Metal matrix
}

\author{
Naomie Beolle Songwe Selabi ${ }^{*}$, Arnaud Regis Kamgue Lenwoue ${ }^{2}$, Lesly Dasilva Wandji Djouonkep ${ }^{3,4}$ \\ ${ }^{1}$ Institute of advanced materials and Nanotechnology, Wuhan University of Science and Technology, \\ Wuhan, 430081, China \\ (naobelle123@wust.edu.cn) \\ ${ }^{2}$ Department of Petroleum Engineering, Leak Resistance \& Sealing Technology Research Department, National \\ Engineering Laboratory of Petroleum Drilling Technology, Yangtze University, Wuhan, 43010, China; \\ (regiskamgue@yahoo.fr) \\ ${ }^{3}$ Department of Petroleum Engineering, Applied Chemistry in Oil and Gas fields, Yangtze University, Wuhan, 43010, \\ China \\ ${ }^{4}$ Institute of fine organic chemistry and new organic materials, Wuhan University of Science and Technology, Wuhan, \\ 430081, China; \\ (dasilvasilva3008@wust.edu.cn)
}

\begin{abstract}
In the conversion process of solar photovoltaic energy, the heat generated induces a rise in temperature, resulting in a significant drop of the electricity conversion efficiency for PV system. As the operating temperature plays a major role in the photovoltaic conversion process, cooling the operating surface is thus the key factor to consider in achieving higher efficiency. In this study, numerical investigation of composite Phase Change Materials (PCMs) for Photovoltaic-cooling (PV-cooling) system and a two-dimensional transient heat transfer model based on enthalpy approach were investigated. PCMs such as $\mathrm{CaCl}_{2} \cdot 6 \mathrm{H}_{2} \mathrm{O}$, paraffin wax, RT25, RT27, SP29, n-Octadecane were carefully selected, whereas copper, aluminium, steel, nickel, PVC, polystyrene, polychlorovinyl and polypropylene were used as composite materials in the numerical calculations solved using the computational Fluid Dynamics (CFD) Ansys-Fluent. The numerical results were compared, and validated with similar models realised by Huang and Khanna research groups. The results showed that RT25 sphere has a good compatibility with PV-cooling system, and that the thermal conductivity has no significant influence on PV-temperature, except for large values (low thermal conductivity) plastic material. Numerical simulations showed that the temperature decrease was obvious when the PCM sphere diameter increased, implying that the diameter of the PCM spheres have great effect on PV-temperature.
\end{abstract}

Keywords: PCM, PV, composite, matrix, temperature, Storage

\section{Introduction}

Sudden variations in climate change caused by global warming has results in an increase in temperatures above $2{ }^{\circ} \mathrm{C}$, which according to the $21^{\text {st }}$ summit report of the Intergovernmental Panel on Climate Change (IPCC) will be a great fatality for the planet if it persists. During this submit in Paris, agreement were signed by 196 states, and resolutions taken to prevent the rise in temperatures beyond $2^{\circ} \mathrm{C}$ to limit the environmental damages. ${ }^{[1]}$ To achieve this goal, greenhouse gas emissions could be significantly reduced by employing efficient less-polluting industrial techniques on one hand, and maximizing the use of renewable energies at the expense of fossil fuels on the other. Renewable energy sources can be defined as "energy obtained from the continuous or repetitive currents on energy re-occurring in the natural environment" or as "energy flows which are replenished at the same rate as they are used". ${ }^{[2]}$ Among these energies, we distinguish biomass energy from any organic plant and animal residue, wind energy from wind, and solar energy from sun rays. Solar (thermal or photovoltaic) is the most abundant renewable energy source in our current era, and has been extensively apprehended due to its simplicity and good energy efficiency via photovoltaic cell. Photovoltaic also called solar cells are electronic devices that convert sunrays directly into electricity. ${ }^{[3]}$ In order to make photovoltaics a more mainstream and pragmatic energy source, the efficiency of solar panels need to be improve radically. In 1975, Telkes was the first to apply phase change materials technology for energy storage. He also demonstrated that the PCMs could extract or grasp the energy during their 
melting/solidification processes. Aware of the enormous potential for energy that can potentially be extraction from these materials; the latter recently became very attractive for solar applications, especially photovoltaics. Amount the PV-cooling technology systems classified by Chandel and al. ${ }^{[4]}$, the PCM-PV-cooling technology is the most profitable, due to their ability to delay the temperature rise of panel without any further electricity consumption. The heat stored can be reused which further enhances the system efficiency. ${ }^{[5]}$

Some studies on the numerical investigations of photovoltaic PCMs are summarized; Cellura and al., ${ }^{[6]}$ made a theoretical analysis by using Comsol Multiphysics, a partial differential equations (PDEs) solver to simulate and improve the efficiency of the thermal behaviour of PV-PCM system, while Biwole and al., ${ }^{[7]}$ used the Computational Fluid Dynamics (CFD) modelling software to simulate the thermo-physical properties of PCM in PV system. Here, the PCM was added at the back of the solar panel to maintain the PV cells temperature below $40{ }^{\circ} \mathrm{C}$ for $2 \mathrm{~h}$. Xiang and al. ${ }^{[8]}$ used a hydride system with PCM and air medium to cool the PV cell and increase the efficiency, where the stored energy could be used for other applications. Khanna and al., ${ }^{[9]}$ study the effect of varying the operating conditions (wind azimuth angle i.e. wind direction, wind velocity, melting temperature of PCM and ambient temperature) on the PV-cell, while Khanna et al., used the fins in a PV-PCM system to optimize the PV-cell efficiency. They use Ansys software to study the effect of fin thinness, length and the spacing between two fins. Their system was able to maintain the PV-cell temperature below $30{ }^{\circ} \mathrm{C}$ for approximatively $4 \mathrm{~h}$. Benlekkam and al., ${ }^{[10]}$ further showed that the use of fins could improve the PV cells efficiency by $2 \%$. Recently, Sathe and al., ${ }^{[1]}$ reported that the increase in the inclination angle of PV-PCM system reduces the time required for melting PCM, thereby increasing the PV surface temperature. Therefore, based on this knowledge on the advances in PCMs, the aims of this work was to propose a new model with a composite PCM to cool the PV-cells in order to improve the efficiency of the PV-system. We thereby applied Ansys-Fluent software to investigate the thermo-physical properties of the PV-cooling system with composite PCMs integrated.

\begin{tabular}{|c|c|c|c|}
\hline \multicolumn{4}{|c|}{ Nomenclature } \\
\hline$\delta$ & depth of PCM container $(m)$ & & $(\mathrm{rad})$ \\
\hline$B$ & liquid fraction of $P C M$ & $\Delta \mathrm{T}$ & phase change zone $(K)$ \\
\hline$C_{p}$ & specific heat capacity $(\mathrm{J} / \mathrm{kg} \mathrm{K})$ & $\varepsilon$ & emissivity for long wavelength radiation \\
\hline$D$ & Dirac delta function & $\eta P V$ module & $\begin{array}{l}\text { solar radiation to electricity conversion efficiency of } P V \\
\text { module }\end{array}$ \\
\hline$F$ & view factor between surfaces & $\mu$ & dynamic viscosity of air $(\mathrm{kg} / \mathrm{ms})$ \\
\hline$g$ & acceleration due to gravity $\left(\mathrm{m}^{2} / \mathrm{s}\right)$ & $v$ & kinematic viscosity of air $\left(\mathrm{m}^{2} / \mathrm{s}\right)$ \\
\hline$G$ & heat generation $\left(\mathrm{W} / \mathrm{m}^{3}\right)$ & $\rho$ & density $\left(\mathrm{kg} / \mathrm{m}^{3}\right)$ \\
\hline$G r$ & Grashof number & $\rho \mathrm{PV}$ & reflectivity of the top surface of the $P V$ module \\
\hline$H$ & convective heat transfer coefficient $\left(\mathrm{W} / \mathrm{m}^{2} \mathrm{~K}\right)$ & $\sigma$ & Stefan-Boltzmann constant $\left(W / m^{2} K^{4}\right)$ \\
\hline$I_{T}$ & solar radiation on tilted surface $\left(\mathrm{W} / \mathrm{m}^{2}\right)$ & \multicolumn{2}{|c|}{ Abbreviation } \\
\hline$K$ & thermal conductivity $(\mathrm{W} / \mathrm{m} \mathrm{K})$ & BICPV & building integrated concentrated $P V$ \\
\hline$L$ & length of the system $(\mathrm{m})$ & EVA & ethylene vinyl acetate \\
\hline$L_{c h}$ & characteristic length $(\mathrm{m})$ & PCM & phase change material \\
\hline$L_{h}$ & latent heat $(\mathrm{J} / \mathrm{kg})$ & PV & photovoltaic \\
\hline$P$ & pressure $(\mathrm{Pa})$ & \multicolumn{2}{|l|}{ Subscripts } \\
\hline $\operatorname{Pr}$ & Prandtl number of air & a & ambient \\
\hline$Q_{L}$ & rate of heat loss from the top surface $\left(\mathrm{W} / \mathrm{m}^{2}\right)$ & $\mathrm{c}$ & critical \\
\hline$R_{e}$ & Reynolds number & for & forced convection \\
\hline$S_{h}$ & solar radiation converted into heat in the system $\left(\mathrm{W} / \mathrm{m}^{2}\right)$ & $\mathrm{Ma}$ & Matrix \\
\hline$t$ & time $(s)$ & 1 & liquid phase \\
\hline$T$ & temperature $(K)$ & nat & natural convection \\
\hline$T_{m}$ & peak melting temperature of PCM $(K)$ & $\mathrm{p}$ & $P C M$ \\
\hline$u$ & velocity of melted $P C M(\mathrm{~m} / \mathrm{s})$ & $\mathrm{s}$ & solid phase \\
\hline & wind velocity $(\mathrm{m} / \mathrm{s})$ & $\mathrm{t}$ & top surface \\
\hline \multicolumn{2}{|c|}{ Greek symbols } & $\mathrm{x}$ & $x$ direction \\
\hline$\beta$ & tilt angle of the panel (rad) & $\mathrm{y}$ & $y$ direction \\
\hline$\beta_{c}$ & thermal expansion coefficient of PCM $(/ K)$ & & \\
\hline$\gamma$ & Liquid volume fraction & & \\
\hline
\end{tabular}




\section{Experimental Model and Numerical Equation}

Here four types of surfaces were involved as shown in Fig. 1. The first is the PV-panel surface (glass, silicon, teldar, EVA) in sky-blue; the second is the composite material surface in dark-orange; the third PCM surface in violet colour and and fourth the aluminium box in brown colour. The aluminium box container is a mixture of PCM and other solid materials. materials. The PCM was introduced into the solid material during it fabrication. Gamma $(\gamma)$ represent the inclination angle of the system. We applied the symmetry boundary condition at the top and bottom of the aluminium box; while the backside is thermally insulated. In this study, the following boundary conditions were considered;

- The initial temperature of the system is ambient $\left(\mathrm{T}_{\mathrm{amb}}\right)$; because the energy is adsorbed at the silicon surface;

- The effect of the radiation is apply at the glass layer with emissivity ( $\varepsilon t$ ), the rear surfaces of the system respectively carries the value h;

- The variations in the thermal properties of the PCM are independent of the temperature, however, they are different for solid and liquid phases;

- The properties of the PCM in solid and liquid phases were homogeneous and isotropic, and inside having the melted PCM;

- The flow was considered incompressible and laminar;

- The radiation condition is apply at the top and bottom of the PV with emissivity $\varepsilon_{\mathrm{t}}$ and $\varepsilon_{\mathrm{b}}$ respectively.

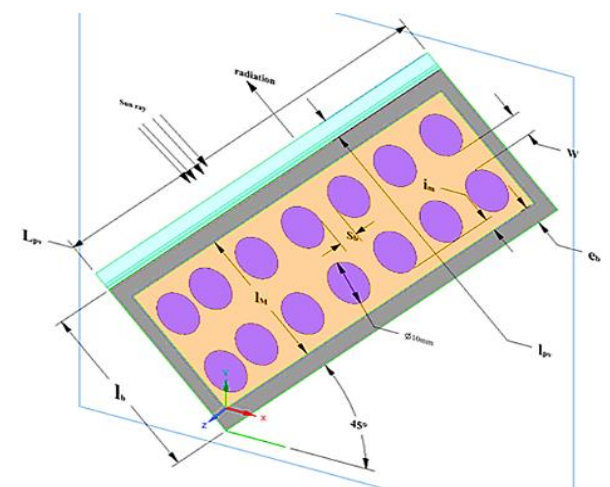

Table 1: Parameters of the model

\begin{tabular}{llcl}
\hline Parameter & Value & Parameter & Value \\
\hline L $_{\text {pv }}$ (PV-length) & $1 \mathrm{~m}$ & E $_{\mathrm{g}}$ (glass thickness) & $3 \mathrm{~mm}$ \\
$\mathrm{I}_{\mathrm{m}}$ (PCM-box) interval & $2.5 \mathrm{~mm}$ & $\mathrm{E}_{\mathrm{E}}$ (EVA thickness) & $1 \mathrm{~mm}$ \\
$\mathrm{~S}_{\mathrm{b}}$ (interval between 2PCM bowl) & $5 \mathrm{~mm}$ & $\mathrm{E}_{\mathrm{t}}$ (Teldar thickness) & $0.1 \mathrm{~mm}$ \\
$\mathrm{l}_{\mathrm{pv}}$ (PV width) & $4.4 \mathrm{~mm}$ & $\mathrm{E}_{\mathrm{s}}$ (Silicon thickness) & $0.3 \mathrm{~mm}$ \\
$\mathrm{l}_{\mathrm{b}}$ (matrix width) & $30 \mathrm{~mm}$ & $\varepsilon_{\mathrm{b}}$ & 0.91 \\
W (space between PCM bowl row) & $5 \mathrm{~mm}$ & $\varepsilon_{\mathrm{t}}$ & 0.85 \\
$\mathrm{e}_{\mathrm{b}}$ (box thickness) & $4 \mathrm{~mm}$ & $\gamma$ & $45^{\circ}$ \\
& \multicolumn{3}{c}{ Number of PCM bowl } \\
\end{tabular}

Figure 1: PV-system with composite PCM

\subsection{The aluminium box filled with composite material: PCM spherical bowls / metal.}

Here, the PCM was introduced during its manufacturing into the cavities of a rectangular box (1000mm x $38 \mathrm{~mm} \times 4 \mathrm{~mm}$ ) whose walls are made of aluminium with the interior concrete made of a melted metal at high temperature, which hardened at room temperature. The amount of PCM in the box represents about $22-67 \%$ by surface.

The 2-D unsteady governing equations of energy and momentum heat transfer are solved by using the simple implicit finite volume method with Fluent 2020 R1. In addition, the Boussinesq approximation Comsol was adopted to count for the change in density of the PCM in the liquid phase with respect to temperature. Below are the defined parameters and abbreviations used in this investigation.

Due to the reflection of the PV, the entire sunray radiation incident that arrives at the surface of the PV (IT) is not totally converted in to energy. A fraction $\left(\rho_{P V} I_{T}\right)$ is lost due to reflection and the rest $(1-\rho P V) I T$ absorbed by the system. Part of the absorbed radiation is used for electricity production and the rest $(\mathrm{Sh})$ converted into heat.

$$
S h=\left(1-\rho_{P V}-\eta_{P V \text { module }}\right) I_{T}
$$

$\eta_{P V \operatorname{module}}$, represents the solar radiation efficiency conversion to electricity of the PV module.

The main contribution to the energy stored by the system owes only to the PCM, so, the stored energy (Qs) at time interval is given by: 


$$
Q_{S}=\left\{\begin{array}{cc}
m c_{S\left(T_{P C M}-T_{a m b}\right)} & \text { if } T_{a m b}<T_{P C M}<T_{M} \\
m C_{S}\left(T_{M}-T_{a m b}\right)+H & \text { if } T_{P C M}=T_{M} \\
m C_{S}\left(T_{M}-T_{a m b}\right)+H+m c_{l}\left(T_{P C M}-T_{M}\right) & \text { if } T_{P C M}>T_{M}
\end{array}\right.
$$

$\mathrm{T}_{\mathrm{m}}$ is the melting temperature, $\mathrm{T}_{\mathrm{PCM}}$ the PCM temperature, $\mathrm{H}$ for latent heat of fusion of PCM, and $\mathrm{T}_{\mathrm{amb}}$ is the ambient temperature. The complete balance of energy of the system is writing as:

$$
\alpha \tau I_{T} \Delta t=\eta_{P V} I_{T} \Delta t+U_{l}\left(T_{P}-T_{a m b}\right) \Delta t+Q_{S}
$$

$\mathrm{T}_{\mathrm{P}}$ is the $\mathrm{PV}$ cell average temperature, $\mathrm{U}_{1}$ the overall heat transfer coefficient.

The inclination angle of the system is $45^{\circ}$; based on Khanna et al. ${ }^{[12]}$ study, the Nusselt number $(\mathrm{Nu})$ and the Rayleigh (Ra) number at the top and bottom of the PV can be writing as follow:

$$
\left\{\begin{array}{c}
N u_{b}=\left[0.825+\frac{0.387(R a \sin \theta)^{1 / 6}}{\left[1+(0.492 / P r)^{9 / 16}\right]^{8 / 27}}\right]^{2} \\
N u_{t}=0.13\left\{(R a)^{1 / 3}-\left(G r_{C} P r\right)^{1 / 3}\right\}+0.56\left(G r_{C} P r \sin \theta\right)^{1 / 4}
\end{array}\right.
$$

Where Pr is the Prandtl number of air, $\mathrm{Gr}_{\mathrm{c}}$ is the critical Grashof number $=1.327 \times 10^{10} \exp \left\{-3.708\left(\frac{\pi}{2}-\theta\right)\right\}$ and $\mathrm{Ra}$ is the Rayleigh number, which is given by: ( $\mathrm{v}$ is the velocity in $\mathrm{m} / \mathrm{s}$ ).

$$
R a=\frac{g\left(T_{l, a v g}-T_{a m b}\right) L_{c h}{ }^{3} P r}{\left(0.25 T_{l, a v g}+0.75 T_{a m b}\right) v^{2}}
$$

\subsection{PCM System Equation}

The liquid fraction varies mildly and continuously across the mushy region. This mushy zone is display by the governing equations to express the phase change phenomena.

$$
\frac{\partial \rho}{\partial t}+\nabla \cdot(\rho u)=0
$$

Where $\rho$ is the density in $\mathrm{kg} / \mathrm{m}^{3}$ and $u$ the speed in $\mathrm{m} / \mathrm{s}$.

The conservation of the momentum is given by:

$$
\frac{\partial u}{\partial t}+(u . \nabla) u=-\frac{1}{\rho} \nabla p+v \nabla^{2} u+F
$$

Where $\mathrm{v}$ is the kinematic viscosity $\left(\mathrm{m}^{2} / \mathrm{s}\right), \mathrm{p}$, pressure in the fluid $(\mathrm{Pa})$

Starting from Eq (6) and Eq (7) and considering that there is heat conversion during the phase change, the heat equations can be expressed by:

$$
\rho c_{p} \frac{\partial T}{\partial t}+\rho c_{p} u . \nabla T=\nabla \cdot(k \nabla T)
$$

$c_{p}$ Specific heat capacity (J/kg.K), k: thermal conductivity of the material (W/m.K), T: temperature of the heat carrier fluid (K). During the phase change process, $\mathrm{Eq}(9)$ can express $\mathrm{k}^{[13]}$ as follows

$$
k=k_{s} \theta_{1}+k_{l} \theta_{2}
$$

$\mathrm{k}_{\mathrm{l}}$ and $\mathrm{k}_{\mathrm{s}}$ are the thermal conductivity of the material at the solid and liquid state, $\theta_{2}, \theta_{1}$, with dimensionless constants expressed with respect to the liquid volume fraction of PCM during the phase change expressed by Eq (10):

$$
\theta_{1}=1-\gamma ; \theta_{2}=\gamma
$$

Where $\gamma$ is the liquid volume fraction in the PCM, and a function of temperature defined by the system Eq (11) $)^{[14]}$ : 


$$
\gamma(\mathrm{T})=\left\{\begin{array}{c}
0, \quad \mathrm{~T}<\mathrm{T}_{\text {Solid }} \\
\frac{\mathrm{T}-\mathrm{T}_{\text {Solid }}}{\mathrm{T}_{\text {liquid }}-\mathrm{T}_{\text {Solid }}} \\
1, \quad \mathrm{~T}>\mathrm{T}_{\text {liquid }}
\end{array}, \mathrm{T}_{\text {Solid }}<\mathrm{T}<\mathrm{T}_{\text {liquid }}\right.
$$

While using Eq (11) above, F can be expressed as a function of $\gamma$; where $\mathrm{F}$ is the acting force on the cylinder during the the heat transfer process. ${ }^{[15]}$ :

$$
F=A \frac{(1-\gamma)^{2}}{\gamma^{3}+c}
$$

Where $\mathrm{c}=0.001$ is a small computational constant used to avoid division by zero, and $\mathrm{A}$ is a constant reflecting the morphology of the melting front. This constant is a large number, usually $10^{4}-10^{7}$. A value of $\mathrm{A}=10^{5}$ has been used in the literature. $\mathrm{C}_{\mathrm{p}}$ is a temperature dependent variable, expressed by $\mathrm{Eq}(13)^{[16]}$ :

$$
c_{p}=\left\{\begin{array}{c}
c_{p s} ; T<T_{S} \\
\frac{1}{2}\left(c_{p_{s}}+c_{p_{l}}\right)+H \frac{1}{\Delta T} ; T_{s}<T<T_{l} \\
c_{p l} ; T_{l}<T
\end{array}\right.
$$

The portion where the PCM temperature is solid and liquid can be express as $T_{s}=T_{m}-\Delta T / 2$ and $T_{l}=T_{m}+\Delta T / 2, \Delta T$ is the region of phase change material.

\subsection{Solid system (PV, aluminium box and composite materials)}

In the aluminium box, the temperature of any $i$ layer of the PV with the composite material in $\mathrm{x}$ and $\mathrm{y}$ direction, at any time is defined by:

$$
\rho c_{P} \frac{\partial T}{\partial t}=k\left(\frac{\partial^{2} T}{\partial x^{2}}+\frac{\partial^{2} T}{\partial y^{2}}\right)+G_{P V}
$$

The boundary conditions are:

$$
\begin{gathered}
k_{g l} \frac{\partial T_{g l}}{\partial y}=q_{t, t} \text { at the top of the glass surface, } \\
\left.k_{P V, i} \frac{\partial T_{P V, i}}{\partial x}=k_{P V, i} \frac{\partial T_{P V J+1}}{\partial x} \text { and for PV surface interface (for } \mathrm{i}^{\text {th }} \text { and }[\mathrm{i}+1]^{\mathrm{th}}\right) \\
k_{A l} \frac{\partial T_{A l}}{\partial y}=k_{M a} \frac{\partial T_{M a}}{\partial y}
\end{gathered}
$$

The equation at the interface of Aluminium and composite material surface normal to $y$-axis is;

$$
\mathrm{k}_{\mathrm{Al}} \frac{\partial \mathrm{T}_{\mathrm{Al}}}{\partial \mathrm{x}}=\mathrm{k}_{\mathrm{Ma}} \frac{\partial \mathrm{T}_{\mathrm{Ma}}}{\partial \mathrm{x}}
$$

At interface of Aluminium and composite material surface normal to $\mathrm{x}$-axis is:

$$
\mathrm{k}_{\mathrm{Al}} \frac{\partial \mathrm{T}_{\mathrm{Ma}}}{\partial \mathrm{y}}=\mathrm{k}_{\mathrm{PCM}} \frac{\partial \mathrm{T}_{\mathrm{PCM}}}{\partial \mathrm{y}}
$$

At interface of Aluminium and PCM, surface normal to y-axis:

$$
k_{\text {tel }} \frac{\partial T_{t e l}}{\partial y}=\left\{\begin{array}{c}
q_{t, b} \text { at the bottom surface of teldar for only PV system } \\
k_{A l} \frac{\partial T_{A l}}{\partial y} \text { teldar and aluminum surface interface } \\
\quad \mathrm{T}=\mathrm{T}_{\mathrm{amb}} \text { at } \mathrm{t}=0
\end{array}\right.
$$

The rate of heat loss from the bottom and the sidewalls was 0 because of the perfect insulation.

$$
k_{P C M} \frac{\partial T_{P C M}}{\partial y}=k_{P C M} \frac{\partial T_{P C M}}{\partial x_{x=0}}=k_{P C M} \frac{\partial T_{P C M}}{\partial x_{x=L}}=0
$$

\section{Solution Method and Validation \\ 3.1 Method}

We applied the ANSYS-Fluent R1 to study the behaviour of PV-panel temperature on the PV-composite PCM system. The bowls of PCM have circular holes of $4-7 \mathrm{~mm}$ in radius, placed at a distance of $1-7 \mathrm{~mm}$ to each other. Simulation were performed following the geometry of PV-composite-PCM, constructed by separating bodies (Glass, EVA, Silicon, Teldar, 
Aluminium, Composite layer and PCM ball) with quadratic gird of independence size $(1 \mathrm{~mm} \times 1 \mathrm{~mm})$. CFD code based on the pressure-velocity coupling is accounted by the SIMPLE algorithm whereas residuals of the energy, continuity and velocity were chosen as 10-8, 10-6,10-6 respectively with 13057nodes. Both organics and inorganics PCMs thermoplastic and metal materials (composite) were used in this investigation. Six PCM were selected, five having melting temperature around $26 \pm 3{ }^{\circ} \mathrm{C}$ and one with $53{ }^{\circ} \mathrm{C}$. The thermal properties of PCMs and the solid matrix are provided in Table ( 2 and 3 ). Four metals and four polymers were selected as matrix constituents.

Table 2: Thermo-physical properties of PCM

\begin{tabular}{|c|c|c|c|c|c|c|}
\hline Properties & SP29 & RT27 & RT25 & n-Octadecane & $\begin{array}{c}\text { Paraffin } \\
\text { Wax }\end{array}$ & $\mathrm{CaCl}_{2} .6 \mathrm{H}_{2} \mathrm{O}$ \\
\hline $\begin{array}{l}\text { Thermal conductivity } \\
(\mathrm{W} . \mathrm{m} / \mathrm{K}) \text { solid/liquid }\end{array}$ & 0.6 & $0.24 / 0.15$ & $0.19 / 0.18$ & $0.35 / 0.149$ & $0.29 / 0.21$ & $1.09 / 0.54$ \\
\hline $\begin{array}{l}\text { Heat storage capacity } \\
(\mathrm{kJ} / \mathrm{kg} . \mathrm{K}) \text { solid/liquid }\end{array}$ & 2.0 & $2.4 / 1.8$ & $1.8 / 2.4$ & $1.934 / 2.196$ & 1.77 & $1.46 / 2.13$ \\
\hline Melting temperature ${ }^{0} \mathrm{C}$ & 29 & 300 & 26.6 & 27.2 & 53.3 & 29 \\
\hline Latent heat $(\mathrm{kJ} / \mathrm{kg})$ & 200 & 178 & 232 & 245 & 164 & 200 \\
\hline $\begin{array}{l}\text { Density }\left(\mathrm{kg} / \mathrm{m}^{3}\right) \\
\text { Solid/Liquid }\end{array}$ & $1550 / 1500$ & $870 / 760$ & $785 / 749$ & $814 / 775$ & 822 & 1710 \\
\hline $\begin{array}{l}\text { Viscosity }(\mathrm{kg} / \mathrm{m} . \mathrm{s}) \\
\text { Solid/ liquid }\end{array}$ & 0.00184 & 0.0342 & $1.8 \times 10^{5} / 1.798 \times 10^{-3}$ & $5 \times 10^{-6}$ & $0.13 \mathrm{~mm} \cdot \mathrm{s}^{-2}$ & $2.2 \times 10^{-2}$ \\
\hline
\end{tabular}

Table 3: Thermo-physicals properties of metals and thermoplastic

\begin{tabular}{|c|c|c|c|c|}
\hline Properties-metal & Copper & Steel & Aluminium & Nickel \\
\hline Density $\left(\mathrm{kg} / \mathrm{m}^{3}\right)$ & 8960 & 8030 & 2675 & 8890 \\
\hline Thermal conductivity (W.m/K) & 401 & 16.27 & 900 & 70 \\
\hline Heat storage capacity (kJ/kg.K) & 385 & 502.48 & 211 & 456 \\
\hline Properties-thermoplastic & $\mathrm{PVC}^{[17]}$ & Resin epoxy ${ }^{[16]}$ & Polystyrene ${ }^{[18]}$ & Polypropylene ${ }^{[19]}$ \\
\hline Density $\left(\mathrm{kg} / \mathrm{m}^{3}\right)$ & 1300 & 1147 & 1045 & 900 \\
\hline Thermal conductivity (W.m/K) & 0.19 & 0.19 & 0.14 & 0.16 \\
\hline Heat storage capacity $(\mathrm{J} / \mathrm{kg} . \mathrm{K})$ & 1000 & 1300 & 1250 & 1700 \\
\hline PV materials & glass & teldar & silicon & EVA \\
\hline Density $\left(\mathrm{kg} / \mathrm{m}^{3}\right)$ & 3000 & 1200 & 2330 & 960 \\
\hline Thermal conductivity (W.m/K) & 1.8 & 0.2 & 148 & 0.35 \\
\hline Heat storage capacity (kJ/kg.K) & 500 & 1250 & 680 & 2100 \\
\hline
\end{tabular}

\subsection{Validation Method}

Khanna group, used fins inside of vertical aluminium PCM (RT25) container to enhance the heat and improve the thermal performance of PV-panel. The length $\left(\mathrm{L}_{P V}\right)$, the depth $\left(\mathrm{l}_{\mathrm{b}}\right)$ and the thickness $\left(\mathrm{e}_{\mathrm{b}}\right)$ of the aluminium box were $1 \mathrm{~m}$, $30 \mathrm{~mm}$ and $4 \mathrm{~mm}$ respectively. The inclination angle of the system, the ambient temperature, the incident radiation and the solar radiation absorption coefficient, were chosen to be $45^{\circ}, 293 \mathrm{~K}, 750 \mathrm{~W} / \mathrm{m}^{2}$ and 0.9 respectively. The emissivity for radiation from top and bottom and the heat loss coefficients from front and back of the system were taken as 0.85 , $0.91,10 \mathrm{~W} / \mathrm{m}^{2} \mathrm{~K}$ and $5 \mathrm{~W} / \mathrm{m}^{2} \mathrm{~K}$ respectively. The other outer walls of the system were insulated. They plotted the variation in the temperature of the PV-panel of the system with respect to time. Here, to validate our model of study; we solved the equations by taking similar parameters as those of Khanna and al (2018). ${ }^{[12]}$ The variation of PV-panel temperature with time is represented in Fig. 2, along with their values. According to the calculations, the results differ from the original work within the range of $\pm 1.5^{\circ} \mathrm{C}$. The results show that the temperature stabilizes within the interval (20min $<\mathrm{t}<360 \mathrm{~min}$ ), and increases afterwards. Sellami and al., ${ }^{[17]}$ reported the same trend. The average PV panel temperature in the PV-composite PCM is represent in Fig 2. 
Huang and al., ${ }^{[18]}$ have investigated the study of thermal performance of the PCM in a rectangular aluminium box with RT25 PCM. The length (L) and the depth $(\delta)$ of the PCM container were taken as $132 \mathrm{~mm}$ and $40 \mathrm{~mm}$ respectively. The thicknesses of the aluminium plates at front and back of the PCM layer taken as $4.5 \mathrm{~mm}$. The incident radiation $\left(\mathrm{I}_{\mathrm{T}}\right)$ and the ambient temperature $\left(\mathrm{T}_{\mathrm{amb}}\right)$ were $750 \mathrm{~W} / \mathrm{m}^{2}$ and $20^{\circ} \mathrm{C}$ respectively. The front and back of the system were not insulated while the other outer walls were covered. They reported the variation in the temperature of the front surface of the system with time. To validate our model with these experimental findings, the calculations was carried out with Ansys-fluent R1 by taking similar parameters. Simulations were done with varying values of the Meshing coefficient, the residuals of the energy, continuity and velocity were chosen as $10^{-5}, 10^{-8}$ and $10^{-6}$ respectively. The variation of the front surface temperature with time was plotted in Fig. 2 along with the experimental measured values. The results differ from the original work within the range of $\pm 1{ }^{\circ} \mathrm{C}$. It is noticed that, the temperature is stabilized within the intervals (40-160 min), beyond which, it starts rising again.
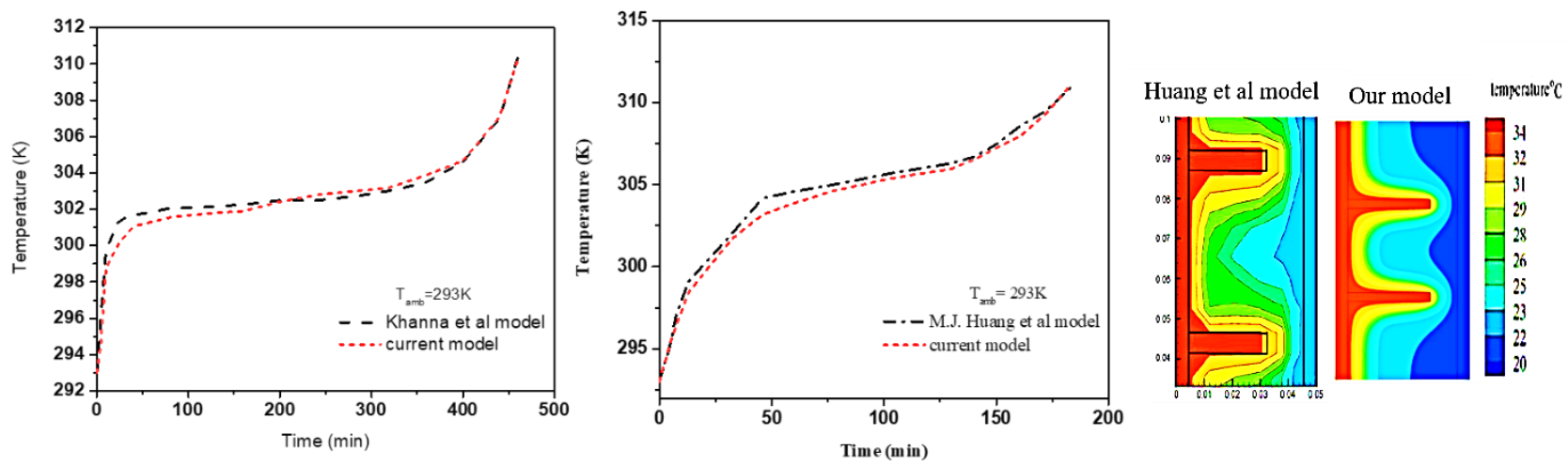

Figure 2: Validation of our model against the simulation result of Khanna et al. [12] and Huang et al. [18].

\section{Results and Discussion}

In order to analyse the performances of the PV-matrix-PCM system, we considered the effect of thermal properties of PCM and matrix materials. The initial temperature of the system was assumed to be $293 \mathrm{~K}$, the flux radiation at the surface of the PV $750 \mathrm{~W} / \mathrm{m} 2$ and the heat transfer coefficient at the front and back of the PV $10 \mathrm{~W} \cdot \mathrm{m}^{-2} \cdot \mathrm{K}^{-1}$ and $5 \mathrm{~W} \cdot \mathrm{m}^{-2} \cdot \mathrm{K}^{-1}$ respectively. Numerical calculations were made for various types of heat exchanger matrix materials having different specific heat, thermal conductivity and density with different PCMs, and their varying effect on melt fraction within 300min interval. To study the effect of the diameter and thickness of PCM sphere on the PV-temperature, simulations were made for different PCM sphere.

\subsection{Effect of the thermal properties of matrix materials and PCMs on PV-temperature}

Calculations were made for six PCMs with different materials: four plastics materials (resin, PVC, PP and PS) and four metals (steel, aluminium, copper and nickel) in order to display the effect of the thermo-physical properties of the matrix. Table 3, displayed the numerical results of the PV-temperature, and melting fraction, with various materials with time. When the value of the thermal conductivity of the matrix increases, the value of PV-temperature and melting fraction increases as well. The values of PV-temperature and melting fractions for plastics materials are substantially equal because their thermal conductivity are in the same range. The continuous PV-temperature and melting fraction with time were plotted in Fig. along with the six PCMs with respect to copper and for the eight composite materials with respect to RT25. 

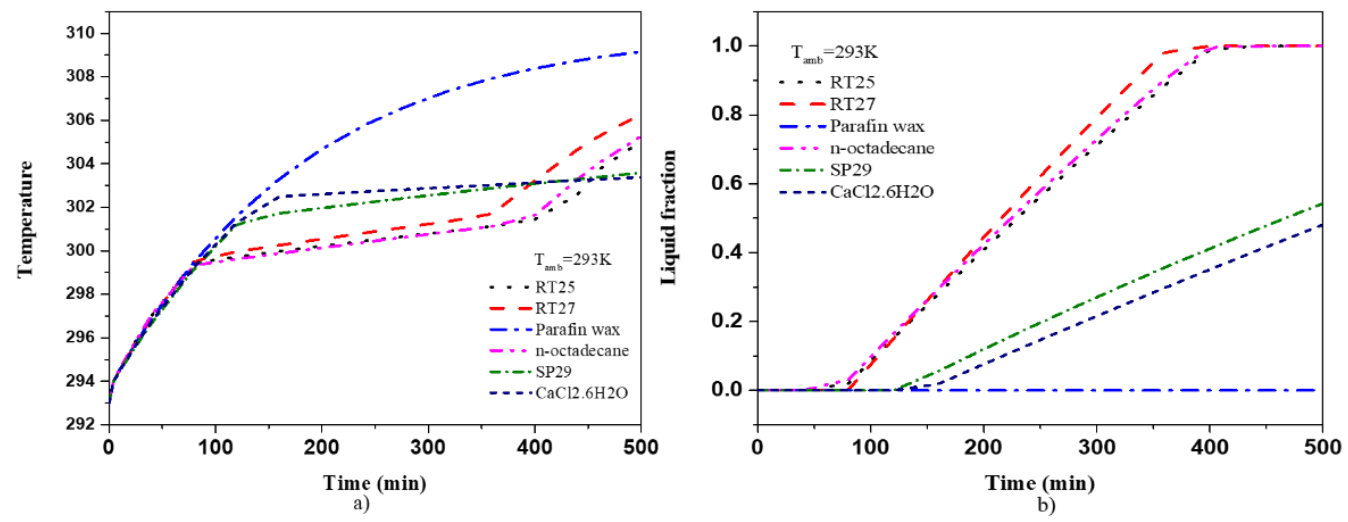

Figure 3: Prediction of PV-temperature and melting fraction with copper

Table 4: Melting fraction and PV-temperature with various matrix materials in 300min

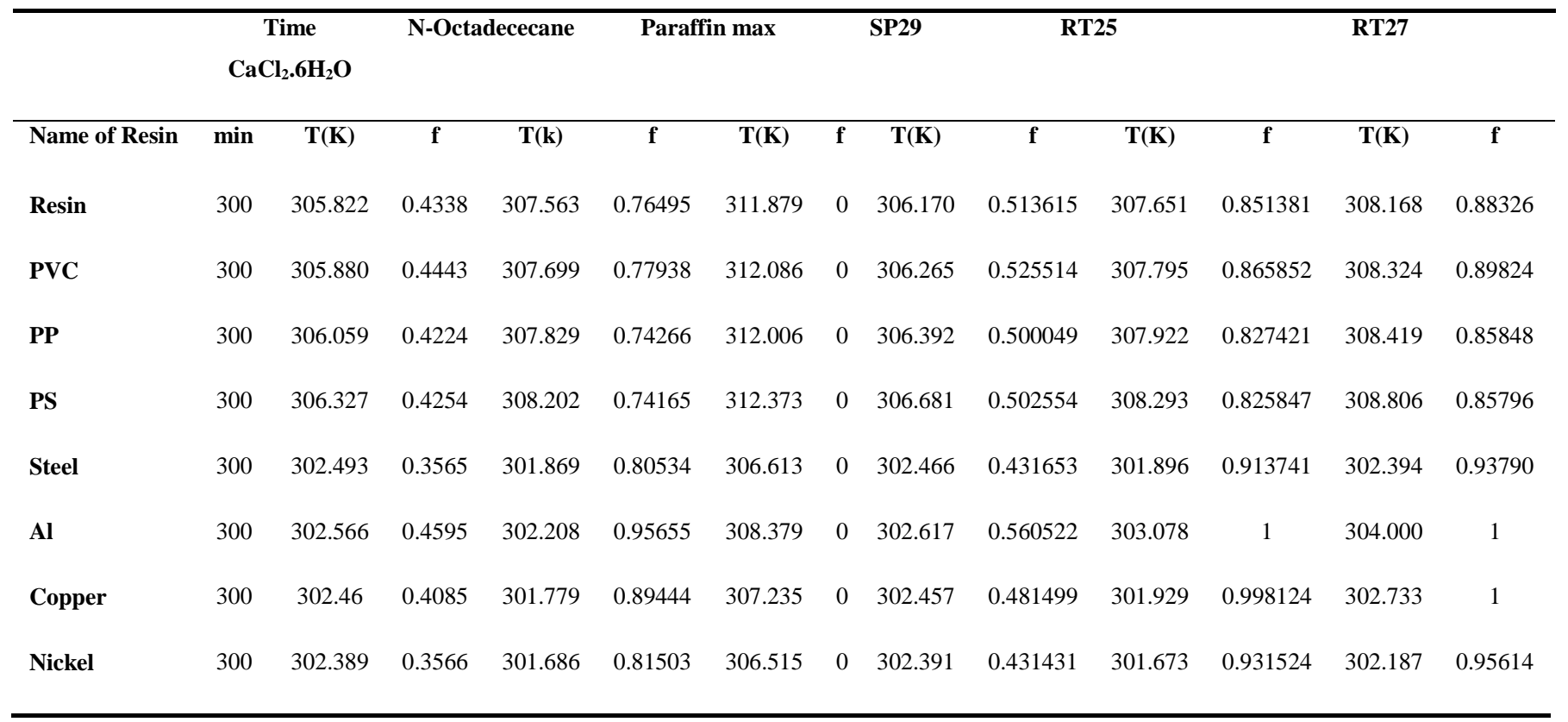

For copper material, stabilization time of PV-temperature was 320min, while for RT25 at lower temperature $(301,93 \mathrm{~K}, 0.998)$ it was $340 \mathrm{~min}$, for $\mathrm{CaCl}_{2} \cdot 6 \mathrm{H}_{2} \mathrm{O}$ with slightly high temperature $(302.46 \mathrm{~K})$ and low melting fractions (0.408), no stabilization is observed with paraffin wax. Form Fig 4 and Table 4, it can be seen that RT25 showed good compatibility with cooling system.

The PV-temperature of the system was low and the melting fraction high compare to the other PCMs at the same time. From this, we demonstrated the effect of the thermo-physical properties of PCMs to make significant contribution on the PV-temperature. For RT25 the time taken to complete melting was 325min and temperature was $302.4991 \mathrm{~K}$ for copper, while it was 0.82 and $308.2938 \mathrm{~K}$ with polystyrene within the same time. The comparison of PV-temperature for various matrix materials within 500min is showed in Fig. 4. There it is observe that the temperature with copper is stable for a much more duration at low PV-temperature as compare to polystyrene, due to the effect of the thermal conductivity, followed by aluminium and steel displaying good tend of stabilization. 

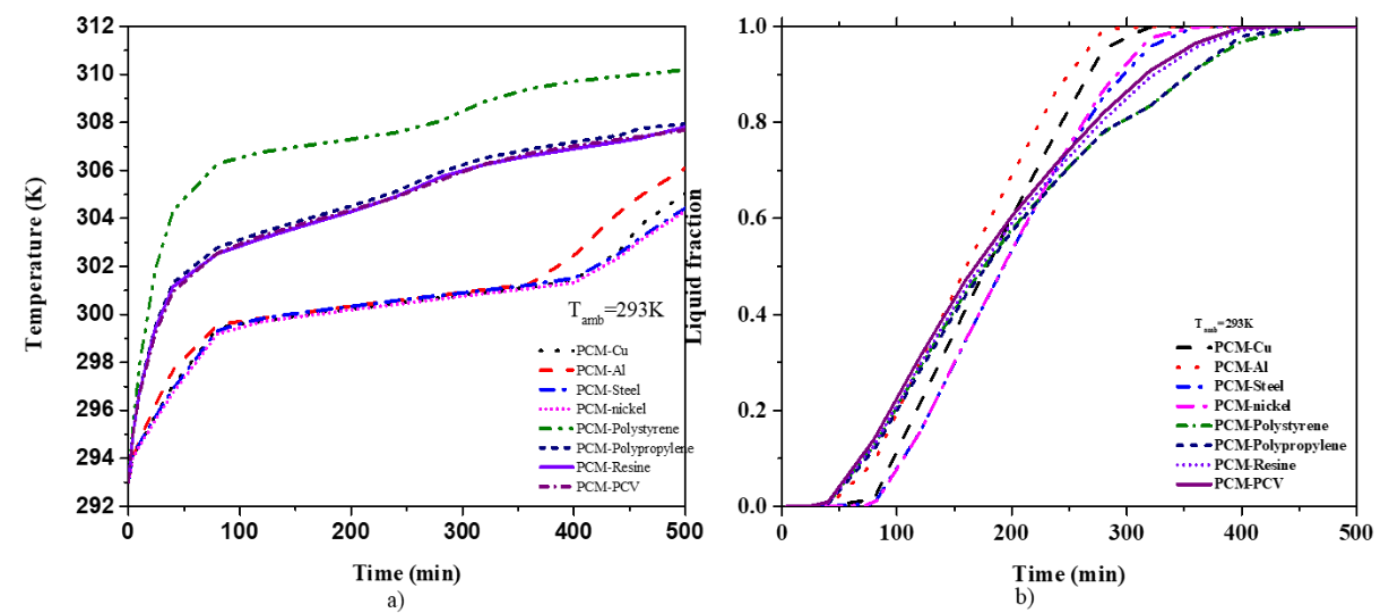

Figure 4: Variation of PV-temperature with RT25 for various matrix material within 500min

From Fig. 4, the effect of thermal conductivity of matrix for plastics materials was dominating when the value of the melting fraction was low. No significant contribution on the melting fraction and PV-temperature is observe for increase in thermal conductivity value of $15 \mathrm{~W} / \mathrm{m} . \mathrm{K}$, although the $\mathrm{PV}$ cell temperature is higher when the matrix is from plastic material. Thus, providing an efficient way to value recycling of plastics materials because their stabilization time interval is longer than that of metal-based matrix.

\subsection{Effect of thickness of the matrix on PV-temperature}

The thickness effect was studied on various matrix materials for RT25 with 0.5,1,2 and $3 \mathrm{~mm}$ thickness. Fig. 5 represents the effect of matrix material thickness on PV-temperature. From this, it can be observed that, when the value of thickness increases, the PV-temperature increase too. Here four types of surfaces were involved as shown in Fig. 1. The first is the PVpanel surface (glass, silicon, teldar, EVA) in sky-blue; the second is the composite material surface in dark-orange; the third PCM surface in violet colour and fourth the aluminium box in brown colour. The aluminium box container is a mixture of PCM and other solid materials.but the increase is minimal. It is clear from the figure that matrix thickness is having almost insignificant effect on PV-temperature.

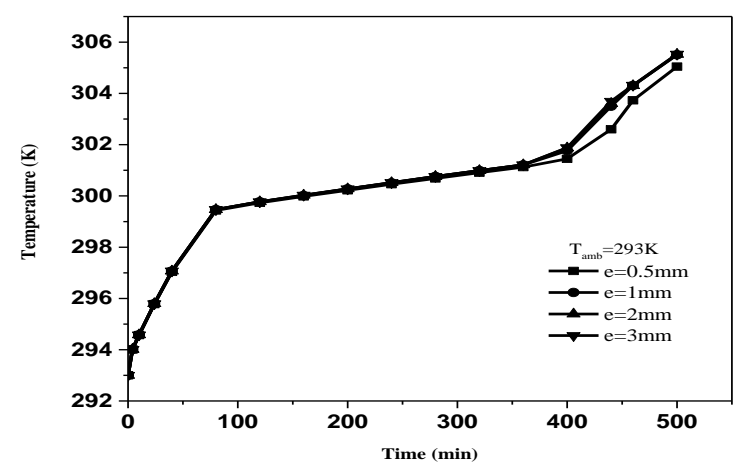

Figure 5: Variation of PV-temperature with different thickness of matrix with copper.

\subsection{Effect of diameter of PCM sphere}

To study the effect of diameter of PCM sphere on PV-temperature, calculations were applied for RT25 with 8, 10, 12 and $14 \mathrm{~mm}$ diameter, which is plotted in Fig 6. Here, it can be seen than increasing the diameter, causes a decrease of PVtemperature and extend the stabilization interval, while the melting fraction decreased. The PV-temperature and melting 
fraction was $(302.5 \mathrm{~K} ; 1)$ with $8 \mathrm{~mm}$ diameter, while it was $(300.9 \mathrm{~K} ; 0.7712),(300.6 \mathrm{~K} ; 0.59761),(300.4 \mathrm{~K} ; 0.45882)$ for $10 \mathrm{~mm}, 12 \mathrm{~mm}$ and $14 \mathrm{~mm}$ diameter respectively within $300 \mathrm{~min}$.
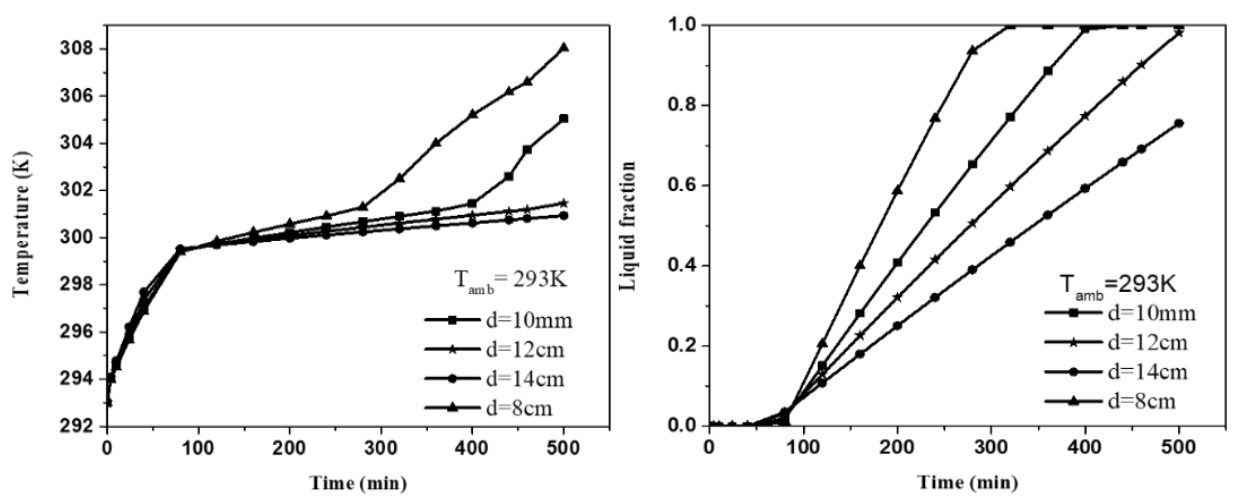

Figure 6: Variation of PV-temperature and Melting fraction of RT25 with different diameter of PCM sphere.

The difference in PV-temperature was not too high compare with the melting fraction from Fig. 6 above, attributed to the varying diameters of PCM sphere, displaying its great effect on PV-temperature and melting fraction. From this we can also assumed that the larger the diameter of the sphere, the larger the interval of stabilization temperatures.

\subsection{Temperature distribution}

The evolution of the temperature on the matrix-PV-PCM system was plotted in Fig. 7 and the temperature distribution of the whole system in Fig. 8. Initially, there is an increase of PV-temperature until it reaches the saturation value and remains constant for a significant amount of time and then increase further beyond this point. This rapid increase at the beginning is due to the low rate of heat extraction by PCM in the solid phase.[19] PV temperature become constant when PCM starts to melt, and increase again once the melting process is over. PCM has store all the energy and absorbed the latent heat, as seen from Fig. 8b, large space with green colour represent the stabilization interval of PV-temperature.

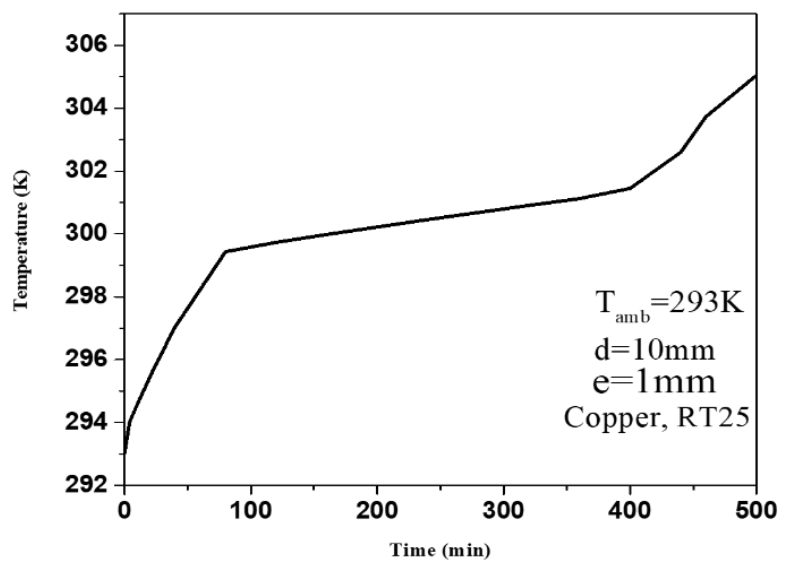

Figure 8: Variation of PV-temperature in Matrix-PV-PCM system 

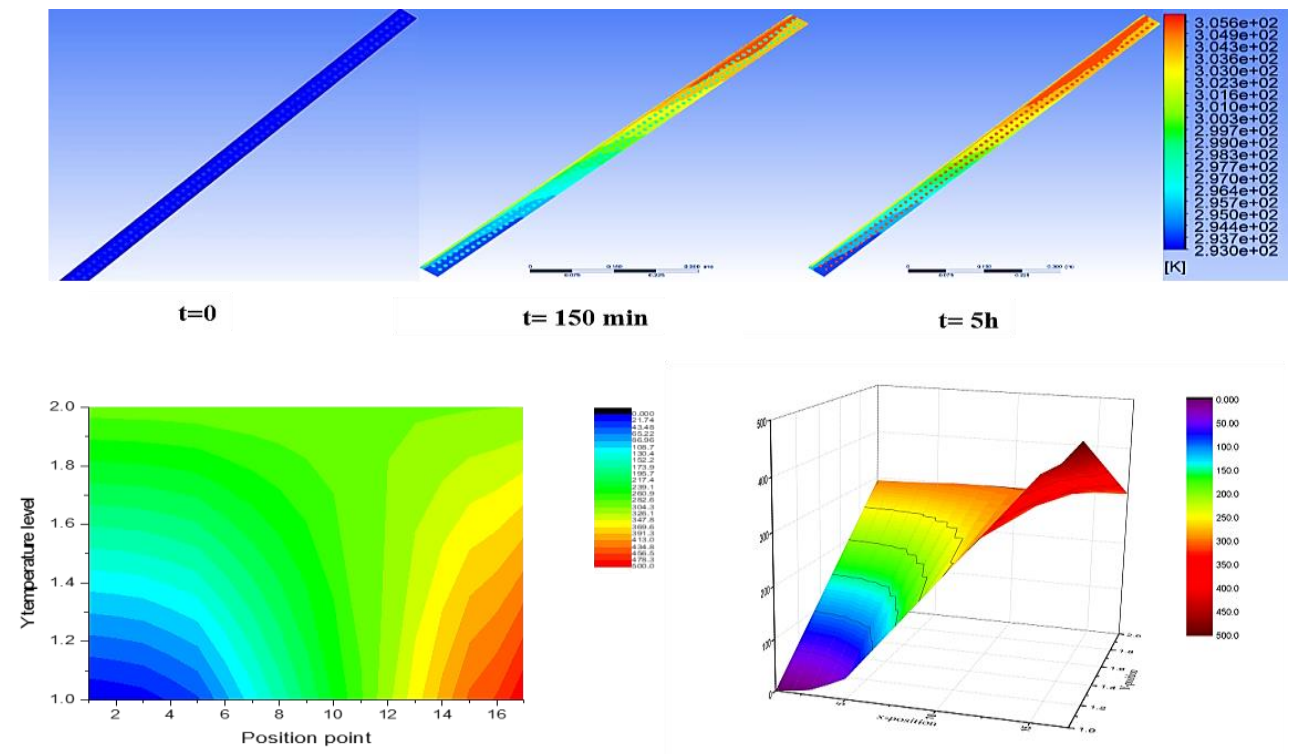

Figure 8: PV-temperature distribution a) distribution with time b) 2D and 3D distribution according to the position.

\section{Conclusion}

A two-dimensional theoretical model base on enthalpy formulation and fully implicit finite distinct methods were developed to analyse the performance of Matrix-PV-PCM systems. A second order continuous and differentiable function was defined for the transition of the PCM. The model was compared, and validated with reference to similar research investigations. The effect of PCMs sphere diameter, matrix materials thermal conductivity and the thickness on PVtemperature were studied. From the above results, it can be conclude that: the selection of the thermal conductivity for matrix materials and melting temperature of PCMs are very important because they have a considerable effect on PV-temperature. PV-temperature decrease as the thermal conductivity of matrix material and the melting fraction increases. Further, the thickness of the matrix material had a negligible impact on the PV-temperature, whereas PCM sphere diameter had a significant effect on PV-temperature and melting fraction. Finally, from this theoretical investigation, the matrix-PV-PCM can be a suitable way to stabilize PV temperature for PV-cooling systems. The diameter of PCM sphere, matrix material need to be carefully selected in order to optimize the stabilization time and improve the performance of PV.

\section{References}

[1] K. Riahi, S. Rao, V. Krey, C. Cho, V. Chirkov, G. Fischer, G. Kindermann, N. Nakicenovic, P. Rafaj. A scenario of comparatively high greenhouse gas emissions. Climatic Change 109, 33 (2011).

[2] L. El Chaar, L.A. lamont, N. El Zein. Review of photovoltaic technologies, Renewable and Sustainable Energy Reviews, 15, 5, 2165-2175 (2011).

[3] B. Parida, S. Iniyan, Ranko Goic. A review of solar photovoltaic technologies. Renewable and Sustainable Energy Reviews, 15, 3, 1625-1636 (2011).

[4] A-E. Kabeel, M. Abdelgaied, R. Sathyamurthy, A. Kabeel. A comprehensive review of technologies used to improve the performance of PV systems in a view of cooling mediums, reflectors design, spectrum splitting, and economic analysis. Environ Sci Pollut Res Int. 28, 7, 7955-7980 (2021).

[5] S.S. Chandel, Tanya Agarwal. Review of cooling techniques using phase change materials for enhancing efficiency of photovoltaic power systems. Renewable and Sustainable Energy Reviews, 73, 1342-1351 (2017). 
[6] M. Cellura, G. Ciulla, V. Lo Brano, A. Marvuglia, Aldo Orioli. A Photovoltaic panel coupled with a phase changingmaterial heat storage system in hot climates, in 25th Conference on Passive and Low Energy Architecture, Dublin (2008).

[7] P. Biwole, P. Eclache, F. Kuznik. Improving the performance of solar panels by the use of phase-change materials, World renewable energy Congress, Sweden, 2953-2960 (2011).

[8] G. Y. Xiang, Guohui. Optimization of building-integrated photovoltaic thermal air system combined with thermal storage, International Journal of Low-Carbon Technologies, 10, 2, 146-156 (2015).

[9] S. Khannaa, K.S. Reddyb, Tapas K. Mallick. Optimization of finned solar photovoltaic phase change material (finned pv-pcm) system, International Journal of Thermal Sciences, 313-322 (2018).

[10] M. L. Benlekkam, D. Nehari, H. Y. Madani. Numerical Performances Study of Curved Photovoltaic Panel, Mechanics and Mechanical Engineering, 22, 4, 1439-1451 (2018).

[11] T. Sathe, A. S. Dhoble, S. Joshi, C. Mangrulkar, V. G. Choudhari. Numerical Investigations of Photovoltaic Phase Change Materials System with Different Inclination Angles, in Advances in Mechanical Engineering, 503-509 (2021).

[12] S. Khanna, S. Sundaram, K.S. Reddy, T. K.Mallicka. Performance analysis of perovskite and dye-sensitized solar cells under varying operating conditions and comparison with monocrystalline silicon cell, Applied thermal engineering, 127, 559-565 (2017).

[13] M. Yizhak. Ionic Liquid Properties: From Molten Salts to RTILs, Electrochemistry, 1, 244 (2016).

[14] Y. Kim, A. Hossain, S Kim, Y N. Hokkaido. A Numerical Study on Time-Dependent Melting and Deformation Processes of Phase Change Material (PCM) Induced by Localized Thermal Input, Two Phase Flow, Phase Change and Numerical Modeling (2011).

[15] O. Bertrand, B. Binet, H. Combeau, S. Couturier, Y. Delannoy, D. Gobin, M. Lacroix, P. Le Quéré, M. Médale, J. Mencinger, H. Sadat, G. Vieira. Melting driven by natural convection: A comparison exercise: first results. International Journal of Thermal Sciences, 38, 1, 5-26 (1999).

[16] A. Seitov, B. Akhmetov, A. G. Georgiev, A. Kaltayev, R. K. Popov, D. B. DzhonovaAtanasova and M. S. Tungatarova. Numerical simulation of thermal energy storage based on phase change materials. Bulgarian Chemical Communications, 48, 181-188 (2016).

[17] M. Zagrouba, A. Sellami, M. Bouaïcha, M. Ksouri. Identification of PV solar cells and modules parameters using the genetic algorithms: Application to maximum power extraction. Solar Energy, 84, 5, 860-866 (2010).

[18] X. Huang, S. Han, W. Huang, X. Liu. Enhancing solar cell efficiency: the search for luminescent materials as spectral converters, Chem Soc Rev. 7, 42, 173-201 (2013).

[19] R. Szczepaniak, R. Rudzki, D. Janaszkiewicz and G. Woroniak. Analysis of Modelling Capabilities of Phase Transitions of the First Kind in Hydrated Sodium Acetate Proceedings of the International Conference on Heat Transfer and Fluid Flow, Prague, 83 (2014). 